\title{
Analysis of Expected Skin Burns from Accepted Process Flare Heat Radiation Levels to Public Passersby
}

\author{
Torgrim $\log 1,2$ \\ 1 Chemistry and Biomedical Laboratory Sciences, Fire Disasters Research Group, Department of Safety, \\ Western Norway University of Applied Sciences, 5528 Haugesund, Norway; torgrim.log@hvl.no; \\ Tel.: +47-900-500-01 \\ 2 Gassco, Inc., 4250 Kopervik, Norway
}

check for updates

Citation: Log, T. Analysis of Expected Skin Burns from Accepted Process Flare Heat Radiation Levels to Public Passersby. Energies 2021, 14, 5474. https://doi.org/10.3390/ en14175474

Academic Editors: Heping Tan and Kang Luo

Received: 28 July 2021

Accepted: 30 August 2021

Published: 2 September 2021

Publisher's Note: MDPI stays neutral with regard to jurisdictional claims in published maps and institutional affiliations.

Copyright: (C) 2021 by the author. Licensee MDPI, Basel, Switzerland. This article is an open access article distributed under the terms and conditions of the Creative Commons Attribution (CC BY) license (https:// creativecommons.org/licenses/by/ $4.0 /)$.

\begin{abstract}
Hot flaring, even from quite high flare stacks, may result in significant heat radiation outside a facility to, e.g., public roads where random passersby may be exposed. The present study suggests a novel method for analyzing a typical flare heat radiation exposure and investigates skin burns that may be inflicted on an exposed person if a facility needs to depressurize in an emergency situation. A typical radiation field from an ignited natural gas vent was taken as the boundary condition, and these values were compared to radiation levels mentioned by the American Petroleum Institute (API 521), e.g., $1.58 \mathrm{~kW} / \mathrm{m}^{2}$ and above. Due to facility perimeter fences along roads in larger industry areas, it was assumed that an exposed person may flee along a road rather than in the ideal direction away from the flare. It was assumed that naked skin, e.g., a bare shoulder or a bald head is exposed. The Pennes bioheat equation was numerically solved for the skin layers while the person escapes along the road. Sun radiation and convective heat exchange to the ambient air were included, and the subsequent skin injury was calculated based on the temperature development in the basal layer. Parameters affecting burn severity, such as heat radiation, solar radiation, and convective heat transfer coefficient, were analyzed. For small flares and ignited small cold vents, no skin burn would be expected for $1.58 \mathrm{~kW} / \mathrm{m}^{2}$ or $3.16 \mathrm{~kW} / \mathrm{m}^{2}$ maximum heat radiation at the skin surface. However, higher flare rates corresponding to, e.g., $4.0 \mathrm{~kW} / \mathrm{m}^{2}$ maximum flare heat radiation to the skin, resulted both in higher basal layer temperatures and longer exposure time, thus increasing the damage integral significantly. It is demonstrated that the novel approach works well. In future studies, it may, e.g., be extended to cover escape through partly shielded escape routes.
\end{abstract}

Keywords: natural gas flaring; passersby; radiant heat exposure; skin burns; modeling

\section{Introduction}

Most hydrocarbon processing plants and gas transport systems operate at high pressures, i.e., up to and even above 100 bar. During process upsets, leaks, and other emergency situations, blowdown and vent/flare systems are recognized as very important safety barriers. During hot flaring, the released gas inventory is burned at the flare tip. Depending on the size and pressures, flare rates up to 1000 tons per hour may be experienced. From quite high industrial flare stacks, this flaring may result in significant heat radiation levels inside the facility, i.e., inside the fenced-off area. However, also outside the facility perimeter, the heat radiation may be significant, e.g., at public roads where random passersby may be exposed.

Smaller facilities are often designed with cold vents, i.e., where the flare is usually not intentionally ignited. This type of pressure relief results in high environmental impacts due to the release of methane and non-methane volatile organic components (nmVOC). Methane, in particular, has a very high global warming potential. Due to such environmental impacts, cold flaring is likely to be banned in the future in several countries. The flares then need to be redesigned for combustion and may then result in high heat flux levels 
beyond the borders of the facility. It is also observed that cold vents have ignited and thus resulted in flaming combustion.

During planned flaring, public access close to the facility perimeter may temporarily be restricted, and the flaring may be performed at low rates thus preventing excessive heat exposure. However, during an emergency requiring immediate depressurization, any passerby may become exposed and may be expected to flee the zone due to the heat radiation and noise levels associated with the flaring. The question may then be raised regarding what skin damage can be expected, if any, during the escape through fast walking or running to an area with lower heat flux levels, or behind objects shadowing the heat radiation. In industrial areas, public roads may go along facilities with high fences, preventing the escape directed away from the radiation source, i.e., the escape must follow a road or a pavement to a safer location. Sun radiation may add to the radiation levels experienced by the fleeing person, and any wind may heat or cool the fleeing person dependent on the ambient temperature and the wind strength. All in all, this person may be expected to move toward a safer area while being exposed to gradually lower heat radiation levels. Research on this type of varying heat exposure has not been discovered thus far. However, analyzing the temperature development in exposed skin may be a way forward to study this in more detail.

Systematic approaches for studying skin burns due to heat exposure were initiated following World War II. Several important research studies on thermal skin injury were then published in The American Journal of Pathology. These studies included heat transport to, and within, porcine skin and included temperature measurements [1]. The significance of exposure time and skin surface temperature in causing cutaneous burns [2] was analyzed. Pathology and pathogenesis were also analyzed regarding cutaneous skin injury on pigs [3] The research demonstrated that both the temperature and the exposure time influenced the severity of the burns analyzed. Additionally, a temperature threshold for skin injury was suggested. Several studies refer to temperature in excess of $44^{\circ} \mathrm{C}$ for developing skin burns $[4,5]$. For hot liquid scalding, other studies refer to $43^{\circ} \mathrm{C}$ as the threshold temperature for developing skin injury [6]. "Skin temperature" development has also been studied in physical simulators during exposure to controlled heat flux levels [7]. A damage development following an Arrhenius type equation is often assumed. Thus, it is assumed that damage increases exponentially with excess temperature and increases linearly with time.

The pain receptors of human skin are located at about $0.1 \mathrm{~mm}$ depth, and it is generally accepted that the threshold temperature for pain is $44.8^{\circ} \mathrm{C}[8,9]$. This temperature is above the threshold for slow skin injury development. However, burns usually involve much higher basal layer temperatures than $44.8^{\circ} \mathrm{C}$. Thus, the pain signal provides an appropriate warning about potential excessive skin heating. In burn scenarios, the skin heating is indeed often very rapid. Thus, the damage develops while the exposed person is warned about the possible dangerous heat exposure. While some burns result from very rapid excessive heat exposure, e.g., scalding by hot water, porridge, etc., flare radiation heat exposure outside the facility perimeter results in slower skin heating. The victim may, however, use some time to move away from the heat exposure, and may flee a long distance while gradually being exposed to lower heat flux levels. As opposed to scalding, elimination of the heat source and cooling the heat-exposed skin by tempered water are not viable options while fleeing from heat radiation exposure.

In some situations involving simple boundary conditions, heat exposure of the skin may be studied by analytic mathematics [10]. However, in a flare heat radiation situation, such solutions are too limited for managing the complex boundary conditions involved. Numerical modeling allows for the required flexibility in dynamic boundary conditions, in particular, gradually reduced radiative heat flux while fleeing. Additionally, it allows for analyzing the situation at hand including realistic properties of the involved heat sources, i.e., the flare and sun heat radiation, the skin layers, blood perfusion, and metabolic heat production. Numerical modeling also allows for boundary conditions changing during a modeling case where a passerby is exposed and starts fleeing away from the heat exposure. 
Based on these qualities and possibilities, the present study analyzed the heat exposure by numerically solving the Fourier-type heat transfer equation, which also has been used with success by other researchers, e.g., [11-13]. The Pennes bioheat equation was utilized in the present study for assessing the corresponding skin overheating injury (damage integral).

Some recent studies have investigated possible skin burns in low heat flux situations $[14,15]$. Yang et al. [14] studied the heat flow to the skin through firefighting garments exposed to $8 \mathrm{~kW} / \mathrm{m}^{2}$ heat radiation and recorded heat flux to the skin gradually increasing to about $2 \mathrm{~kW} / \mathrm{m}^{2}$. Physiological reactions such as sweat production were considered. The effect of high heat flux early and late during heat exposure has previously been analyzed [16], and it was found that an early heat flux peak gave fewer burns than a similar later peak in heat flux to the skin. The situations analyzed by Yang et al. [14] are therefore different from the flaring cases analyzed in the present case, in which the heat flux decrease with time while a person flees the exposed area. Zhang et al. [15] studied physical work (treadmill) for persons in underwear exposed to a constant $1 \mathrm{~kW} / \mathrm{m}^{2}$ or $2 \mathrm{~kW} / \mathrm{m}^{2}$ heat flux. However, in their study, the persons in the quite stagnant air (less than $0.1 \mathrm{~m} / \mathrm{s}$ ) climate chamber started sweating, thus reducing the net heat flux to the skin. These studies are therefore not directly comparable to the present work, which is unique in analyzing possible passersby exposed to gradually decreasing heat loads in situations where the wind will convectively cool any exposed skin.

The objective of the present study is to analyze temperature development and skin burn injury for selected realistic flare heat exposures to naked skin, e.g., a naked shoulder or a bald head, by numerical modeling while a person is fleeing the area. Parameters influencing burn severity, such as walking or running speed, solar radiation, wind speed, and ambient temperature were analyzed. Modeled heat radiation from a representative flaring case, taking into consideration radiant heat absorption due to air relative humidity, was used as a base case. Attention was given to the API value of $1.58 \mathrm{~kW} / \mathrm{m}^{2}$ heat radiation and twice this level.

The paper is unique in analyzing the skin damage development during the evacuation from a radiant heat source including heat radiation from the flare and the sun, as well as heat transfer to the ambient air. Time-dependent skin temperatures and injury development are presented for selected cases. Conclusions are drawn with respect to the most influential parameters identified and measures that may be introduced to limit the skin injury development during the evacuation.

The theory on involved heat transfer mechanisms, skin layer blood perfusion, and metabolic heat generation, numerical modeling parameters, and damage integral modeling are presented in Section 2. The modeling and the general findings are presented and discussed in Section 3, and the main conclusions are presented in Section 4. A motivation for accomplishing and publishing this study is to analyze the possibility for assessing skin damage in a realistic situation that may occur and present a methodology for future flare radiation risk assessments.

\section{Heat Transfer and Damage Integral}

\subsection{Radiant and Convective Heat to Exposed Skin}

In normal operation, the heat exposure to a passerby outside a petroleum production, compression or transport site will be very low also in the case of pilot ignited flares. The pilot flames ensuring that gas released will be combusted do not emit any noticeable heat radiation. Most flaring incidents are usually associated with maintenance situations where the timing of the flaring and the flaring rates can be selected according to the weather conditions. Flaring in low wind strengths results in a quite vertical flame. However, during an emergency, e.g., a gas leak within the facility that may ignite, depressurization needs to start immediately and at rates as fast as the flare system design allows, to prevent gas leak ignition. If the plant experiences a developed fire, overpressuring possible enclosed volumes and softening of the process equipment and piping may result in an escalation of the incident. Then, it is very important to depressurize the facility as fast as possible to 
prevent an escalation. This may occur when the wind direction is unfortunate regarding exposing areas outside the site fencing, i.e., where passersby may be present, to heat excessive heat radiation.

Inside the site, personnel are generally trained and familiar with the incidents that may occur. They also use protective clothing, gloves, hard hats, etc. which will protect them from high radiative heat fluxes within the site. They can also usually evacuate to safe areas within the site where they will be protected while equipment and piping are depressurized. Any passerby may, however, be wearing only light clothing and may in principle have naked skin exposed to sudden flare radiation. Examples may be, e.g., naked arms, shoulders or a bald head.

A principal sketch of flames from flaring in low wind and in a strong wind blowing toward a passerby is shown in Figure 1. Since the wind bends the flame plume, the flame will be much closer to an exposed person in such windy conditions. Being downwind of the flare, he/she will then be exposed to much more heat radiation than on a calm day. If it blows in the other direction, he/she will be less exposed. When dimensioning the flare system, the credible worst scenario should give the dimensioning parameters, i.e., the strong wind condition, if that is consistent with wind strengths and wind directions experienced at the site.

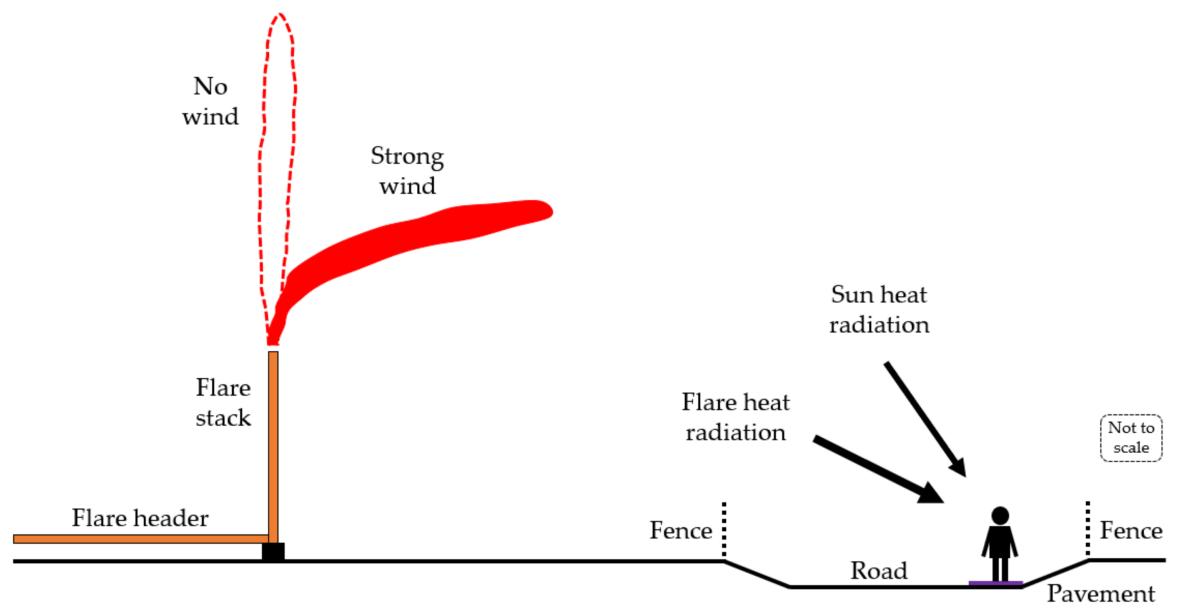

Figure 1. Principal sketch of flare flame heat exposure in varying wind conditions.

\subsection{Skin Heat Transfer Modeling}

The exposed skin will absorb heat radiation from the flare and the sun, as well as heat radiation from objects at the ambient temperature. In windy conditions, i.e., when the flare heat radiation to an exposed person, as presented in Figure 1, is highest, more heat will be exchanged convectively between the skin and the surrounding air. The skin itself will also radiate heat back to the surroundings. These heat fluxes will form the boundary conditions for the skin surface heat transport.

The inward heating of the skin is governed by heat conduction, which may be described by Fourier's law, i.e., the conductive heat flux is a linear function of the temperature gradient as follows:

$$
\dot{q}_{k}^{\prime \prime}=-k \cdot \nabla T\left(\mathrm{~W} / \mathrm{m}^{2}\right),
$$

where $k(\mathrm{~W} / \mathrm{m} \cdot \mathrm{K})$ is the skin thermal conductivity, and $\nabla T(\mathrm{~K} / \mathrm{m})$ is the temperature gradient. The conventional heat balance for bioheat production and heat transfer may be described by the Pennes bioheat equation.

$$
\rho C \frac{\partial T}{\partial t}=-\nabla \cdot \dot{q}_{k}^{\prime \prime}+W_{b} \rho_{b} C_{b}\left(T_{b}-T\right)+Q_{m e t}+Q_{e x t}\left(\mathrm{~W} / \mathrm{m}^{3}\right)
$$


where $\rho\left(\mathrm{kg} / \mathrm{m}^{3}\right)$ is the density of the skin, $C(\mathrm{~J} / \mathrm{kg} \cdot \mathrm{K})$ is the specific heat of the skin, $t(\mathrm{~s})$ is the time, $W_{b}\left(\mathrm{~m}^{3} / \mathrm{m}^{3} \cdot \mathrm{s}\right)$ is the blood perfusion rate, $\rho_{b}\left(\mathrm{~kg} / \mathrm{m}^{3}\right)$ is the density of the blood, $C_{b}(\mathrm{~J} / \mathrm{kg} \cdot \mathrm{K})$ is the specific heat of the blood, $T_{b}(\mathrm{~K})$ is the temperature of the supplied blood, $Q_{m e t}\left(\mathrm{~W} / \mathrm{m}^{3}\right)$ is the metabolic heat generation, and $Q_{\text {ext }}\left(\mathrm{W} / \mathrm{m}^{3}\right)$ is the heat provided by an external heat source.

For heat exposures of short duration, $\mathrm{Ng}$ and Chua [17] found that blood perfusion does not influence the extent of skin burns significantly. This conclusion supports the findings by Lipkin et al. [18], who determined that approximately $20 \mathrm{~s}$ was required for the skin to raise the blood flow. A similar conclusion was also presented by Fu et al. [4]. When escaping from a flaring scenario, the person fleeing may be exposed to excessive heat radiation for much longer periods than $20 \mathrm{~s}$. Thus, in the present study, blood perfusion and metabolic heat generation had to be included in the numerical modeling. Models for blood perfusion and metabolic heat generation, as suggested by Rai and Rai [19], were in the present study, therefore, included when solving Pennes bioheat equation, i.e., Equation (2).

The curve diameter of an exposed shoulder or a bald head is much larger than the expected heat penetration depth while fleeing. Thus, the exposed skin may be treated as one-dimensional, i.e., it may be assumed that the body surface can be treated as a flat surface. This enables analyzing heat flow in one dimension, i.e., dependent on the skin depth ( $x$-dimension) only.

In a scenario where an exposed person is quite a distance from the flare, with heat radiation flux level $\dot{q}_{\text {flare }}^{\prime \prime}(t)\left(\mathrm{W} / \mathrm{m}^{2}\right)$, a moderate skin temperature increase is expected for the scenarios analyzed in the present study. It is, therefore, reasonable to assume that the skin thermal properties are independent of temperature. It should also be noted that any heat radiation from the sun, $\dot{q}_{\text {sun }}^{\prime \prime}$ may add a substantial heat flux to exposed skin during daytime. The worst-case scenario is that both the flare and solar heat radiation are from about the same angle to the person exposed. Thus, these heat fluxes may simply be added.

A shoulder or a bald head will have parts of the skin surface quite perpendicular to these radiating objects. A quite credible scenario, and slightly conservative assumption, is that these heat fluxes hit perpendicular to the exposed skin, as indicated in Figure 2.

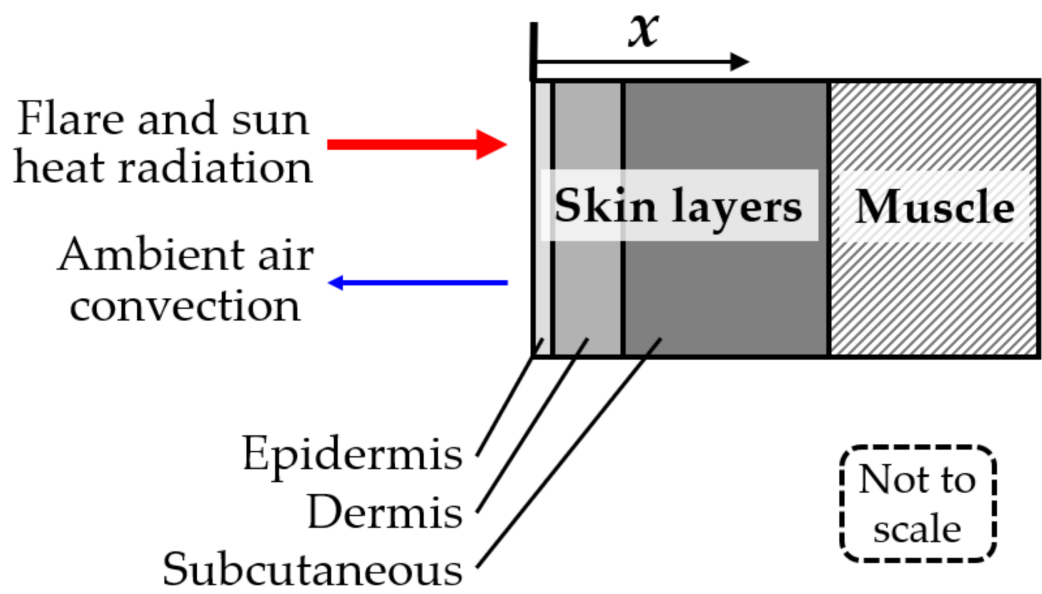

Figure 2. Sketch of the skin and muscle layers and heat fluxes involved in an ignited flare scenario.

In Figure 1, it is assumed that the ambient air is colder than the heat exposed skin surface and that the wind bending the flare flames to some extent will cool the radiant heat exposed skin surface. Though this may not initially be the case in hot climates, this will be the case when skin surface temperatures reach values associated with radiant heat burns.

In real cases, it may take some seconds from the first signs of increased flaring to full depressurization capacity rates. For simplicity in the present study, it was assumed that the flaring happens instantaneously at $t=0$ and onwards. This may not be a very conservative assumption since an exposed person will probably need some time to realize what is transpiring before start fleeing. At $t>0$, heat is radiated to the skin, while increasing 
skin surface temperature results in some heat gradually being lost by convection and heat radiation to the ambient.

The radiative heat loss from the skin may be expressed by

$$
\dot{q}_{\mathrm{rad}}^{\prime \prime}=\varepsilon \sigma\left(T_{a m b}^{4}-T_{s, s}^{4}(t)\right)\left(\mathrm{W} / \mathrm{m}^{2}\right),
$$

where $\sigma\left(5.67 \times 10^{-8} \mathrm{~W} / \mathrm{m}^{2} \mathrm{~K}^{4}\right)$ is the Stefan-Boltzmann constant, and $\varepsilon$ is the emissivity of the skin, which is generally assumed to be 0.98 [20], $T_{a m b}(\mathrm{~K})$ is the ambient temperature, and $T_{S, S}(\mathrm{~K})$ is the skin surface temperature.

The heat loss by convection from the skin surface at temperature $T_{s, S}(\mathrm{~K})$ to the ambient air is given by

$$
\dot{q}_{\text {conv }}^{\prime \prime}=h \cdot\left(T_{s, s}-T_{a m b}\right)\left(\mathrm{W} / \mathrm{m}^{2}\right),
$$

where $h\left(\mathrm{~W} / \mathrm{m}^{2} \cdot \mathrm{K}\right)$ is the convective heat transfer coefficient. This varies with wind speed and the dimension of the object. The convective heat transfer coefficient for a bald head has been studied by several researchers, especially regarding wind chill conditions. Shitzer [21] summarized several such studies and concluded that the study of Osczevski [22], where this was directly measured by heat loss from head mockups were most reliable. Thus, the convective heat transfer coefficient may be expressed by

$$
h=0.23 \cdot(U \cdot \rho / \mu)^{0.6} \cdot k / D^{0.4}\left(\mathrm{~W} / \mathrm{m}^{2} \mathrm{~K}\right)
$$

where $U(\mathrm{~m} / \mathrm{s})$ is the wind speed, $\rho\left(\mathrm{kg} / \mathrm{m}^{3}\right)$ is the ambient air density, $\mu\left(\mathrm{N} \cdot \mathrm{s} / \mathrm{m}^{2}\right)$ is the ambient air viscosity, $k(\mathrm{~W} / \mathrm{mK})$ is the ambient air thermal conductivity, and $D(\mathrm{~m})$ is the head diameter, i.e., here taken as $0.18 \mathrm{~m}$. In, e.g., $10 \mathrm{~m} / \mathrm{s}$ wind and $20{ }^{\circ} \mathrm{C}$ air, the heat transfer coefficient becomes $35.6 \mathrm{~W} / \mathrm{m}^{2} \cdot \mathrm{K}$. However, the wind speed at shoulder height will be lower than the meteorological wind speed, which is usually referred to at $10 \mathrm{~m}$ elevation. Local obstructions may also lower the wind speed close to the ground level. Thus, a more conservative value of $h=20 \mathrm{~W} / \mathrm{m}^{2} \cdot \mathrm{K}$ was adopted in the present study.

To correctly model the net external heat flux to the skin surface, Equation (1) must be solved for the skin layers. Solving Equation (2) numerically allows for including varying boundary conditions for the heat transport to the skin, i.e., a gradually decreasing flare radiation heat exposure while the exposed person flees the area along the pavement, as indicated in Figure 1. To simplify initial conditions, the skin temperature at $t=0$ was conservatively set to $37^{\circ} \mathrm{C}$ [6] for all involved depths, i.e., $0 \leq x \leq \Delta$, where $\Delta(\mathrm{m})$ is the domain size. This includes the skin layers of Table 1. From the onset of the flaring and onwards, i.e., at $t>0$, the heat supply at the surface of the skin, i.e., at $x=0$, is given by

$$
\dot{q}^{\prime \prime}(t)=\varepsilon \dot{q}_{\text {flare }}^{\prime \prime}(t)+\varepsilon \dot{q}_{\text {sun }}^{\prime \prime}+\varepsilon \sigma\left(T_{a m b}^{4}-T_{s, s}^{4}(t)\right)+h_{\text {air }}\left(T_{\text {air }}-T_{s, s}(t)\right) \text { for } t>0,
$$

where the skin emissivity, $\varepsilon$, is generally assumed to be 0.98 [20], i.e., quite close to 1.0.

Table 1. Properties of the affected skin layers (thermal conductivity, $k$, density, $\rho$, and specific heat, $C$, from [6]).

\begin{tabular}{cccccc}
\hline Skin Layer & $\boldsymbol{k}(\mathbf{W} / \mathbf{m} \cdot \mathbf{K})$ & $\boldsymbol{\rho} \mathbf{( \mathbf { k g } / \mathbf { m } ^ { 3 } )}$ & $\boldsymbol{C}_{\boldsymbol{P}}(\mathbf{J} / \mathbf{k g} \cdot \mathbf{K})$ & $\boldsymbol{a}\left(\mathbf{m}^{2} / \mathbf{s}\right)$ & Thickness $(\mathbf{m})$ \\
\hline Epidermis & 0.22 & 1200 & 3600 & $5.1 \times 10^{-8}$ & $60 \& 80 \times 10^{-6}$ \\
Dermis & 0.40 & 1200 & 3600 & $9.3 \times 10^{-8}$ & 0.002 \\
Sub cutaneous & 0.20 & 1000 & 2500 & $8.0 \times 10^{-8}$ & 0.010 \\
Muscle & 0.45 & 1000 & 3800 & $1.2 \times 10^{-7}$ & 0.005 \\
\hline
\end{tabular}

Thus, the skin surface boundary condition is given by

$$
k \frac{\partial T}{\partial x}=\dot{q}^{\prime \prime}(t) \text { for all } t>0 \text { at } x=0,
$$


The inner skin surface, i.e., at $x=\Delta$, boundary condition is for simplicity given by a reflection plane, i.e., in contact with an adiabatic surface.

$$
k \frac{\partial T}{\partial x}=0 \text { for all } t \text { at } x=\Delta,
$$

The domain size, i.e., the skin depth $\Delta$, must be large enough to limit any influence of the skin depth in the modeling. A thickness $\Delta>2 \sqrt{a t}$ is normally required to minimize any influence of a reflectance heatwave of a limited one-dimensional domain [23], where $t$ (s) is the time from the onset of the heating, and $a\left(\mathrm{~m}^{2} / \mathrm{s}\right)$ is the thermal diffusivity of the solid given by

$$
a=\frac{k}{\rho C}\left(\mathrm{~m}^{2} / \mathrm{s}\right)
$$

By including the subcutaneous layer, the domain becomes much larger than the required $\Delta>2 \sqrt{a t}$ criterion for the cases studied in the present work.

Values for the different skin layer thicknesses vary in the literature. This variation is probably a result of individual differences, as well as variation in skin layer thickness on possibly exposed body parts. A thorough summary of skin thicknesses and properties relating to burns are provided by Johnson et al. [6]. The values reported vary from those reported by Millington and Wilkinson [24] but are used also by many other researchers. The epidermis thickness also varies with location, i.e., probably thicker on the outwards facing surface and thinner on the inward-facing surfaces. Abraham et al. [13] used a thickness of $80 \mu \mathrm{m}$ for the epidermal thickness in a study concerning scalding on shoulders. In the present work, an epidermis thickness of $60 \mu \mathrm{m}$ was also studied for sensitivity analysis. The skin properties used in the present study are presented in Table 1.

To obtain numerical stability, the numerical integration time interval, $\Delta t$ (s), must be set to comply with a Fourier number satisfying

$$
F o=a \cdot \frac{\Delta t}{\Delta x^{2}}<0.5,
$$

where $\Delta x(\mathrm{~m})$ is the integration layer thickness. For the numerical integration, an integration layer thickness $\Delta x=10 \mu \mathrm{m}$, and a time interval $\Delta t=2 \times 10^{-4}$ s were used to satisfy the Equation (10) criterium and ensure numerical stability for the muscle layer, i.e., the skin layer with the highest thermal diffusivity. A computer code was written in the $\mathrm{C}++$ language for solving the involved numerical equations within the defined boundary conditions and the respective skin layers.

\subsection{Skin Damage Modeling}

Burns and scalds severity are among laypersons categorized as first-degree, seconddegree, and third-degree burns. More professionally, burns may better be categorized into one of the following categories: (1) superficial (S) burns restricted to the epidermis layer and characterized by minor edema and quick healing; (2) superficial partial-thickness (SP) burns that continue into the outer dermis layer resulting in moderate edema but limited or no scarring (usually less than $1 \mathrm{~mm}$ burn depth); (3) deep partial-thickness (DP) burns extending well into the dermis and heal slowly (typically $1 \mathrm{~mm}$ or more burn depth), resulting in hypertrophic scarring; (4) full-thickness (FT) burns extending through the entire dermis and require skin grafting (burn depths typically deeper than $2 \mathrm{~mm}$ ) [13]. Category $\mathrm{S}$ burns usually correspond to the lay-term first-degree burns, while category SP and DP burns correspond to second-degree burns, and category FT corresponds to third-degree burns.

Cell injuries resulting from excessive skin temperatures and protein breakdown, where collagen is a key protein, can be modeled to evaluate burn severity at the depths of interest. 
The cell injury forming during skin overheating at a particular depth may be expressed by a damage index $\Omega$ [25] as follows:

$$
\Omega(\tau)=-\ln \left(\frac{C_{\tau}}{C_{0}}\right),
$$

where $C_{0}$ and $C_{\tau}$, respectively, represent the concentration (or number) of undamaged cells prior to and after the excessive heat exposure. Heat injury corresponding to $90 \%$ of the cells still being undamaged corresponds to an index of 0.1. A damage index of 1.0 implies that only $36 \%$ of the cells are still not damaged. The rate of skin damage developing as a result of excessive tissue heating can be assessed using an activation energy-based model originally suggested by Henriques and Moritz [26].

$$
\frac{\partial \Omega}{\partial t}=P \exp \left(-\frac{\Delta E}{R T}\right),
$$

where $P(1 / \mathrm{s})$ is a pre-exponential frequency factor, $\Delta E(\mathrm{~J} / \mathrm{mol})$ is the damage activation energy, $R(8.314 \mathrm{~J} / \mathrm{mol} \cdot \mathrm{K})$ is the universal gas constant, and $T(\mathrm{~K})$ is the absolute temperature. Literature data for these damage parameters, i.e., $P$ and $\Delta E$, vary significantly [11]. In the present study, the data originally suggested by Henriques and Moritz [1,26], i.e., $P=3.1 \times 10^{98} 1 / \mathrm{s}$ and $\Delta E=6.28 \times 10^{8} \mathrm{~J} / \mathrm{mol}$, were used while modeling the skin injury.

The accumulated burn damage may finally be obtained by integrating Equation (12) for the time interval where the temperature of the basal layer is $\geq 43.0^{\circ} \mathrm{C}$.

$$
\Omega=\int_{0}^{t} P \exp \left(-\frac{\Delta E}{R T}\right) \mathrm{dt},
$$

As the damage index, $\Omega$, is assessed as an integral, it is often be referred to as a damage integral. Ye and He [27] report damage integral of $\Omega=0.53$ in the basal layer as the limit for superficial (first-order) burns and $\Omega=1.0$ as the limit for superficial partial-thickness (second-order) burns. Calculated damage integrals were compared with these limits to examine skin injury for different flare heat radiation exposure cases. Numerical integration of the damage integral, i.e., Equation (12), was performed in the previously mentioned C++ code. Conveniently, the same integration time interval was used for the damages integral as for the heat transport modeling.

\subsection{The Flaring Scenarios Analyzed}

The flare heat radiation is a result of heat radiation from the soot particles as well as from gas products, e.g., methane $\left(\mathrm{CH}_{4}\right)$ and combustion products such as carbon monoxide $\left(\mathrm{CO}_{2}\right)$ and water $\left(\mathrm{H}_{2} \mathrm{O}\right)$. Dependent on their vibrational modes, these gases can both release and absorb heat radiation. Thus, the heat radiation from a flare is not a continuum as expected from black body soot radiation. Several software codes are developed for flare radiation simulations, e.g., Flaresim or Frustum, while others use computational fluid dynamics modeling by, e.g., Kameleon FireEx (KFX), etc. Based on several tests and working-level projects, the accuracy and usability of KFX have been verified, and the simulation results show a very good result relative to the actual tests performed [28-31]. This is also confirmed in recent modeling studies, e.g., [32]. In KFX, the emissive power at each wavelength based on literature data $[33,34]$ may be calculated, including black body radiation and molecular radiation from the dominant gas molecules, i.e., methane $\left(\mathrm{CH}_{4}\right)$, carbon dioxide $\left(\mathrm{CO}_{2}\right)$, carbon monoxide $(\mathrm{CO})$, and water vapor $\left(\mathrm{H}_{2} \mathrm{O}\right)$.

Outside the flare flame, the dipole moment of the water molecules makes the ambient air humidity absorb some of the heat radiation frequencies emitted from an ignited flare, making this even more complicated. However, e.g., KFX has the possibility to also postprocess atmospheric relative humidity heat radiation absorption at a given distance. Thus, for a given flaring scenario, the remaining heat radiation to a distant point may be calculated when the ambient temperature and relative humidity are known. Results obtained from 
this software were therefore used as input to the skin burns modeling and thus served as an example of heat radiation field for the present study. In principle, any other code could be used as long as it is capable of realistically modeling the flame heat radiation as well as the radiant heat attenuation for the involved wavelengths through the air towards a passerby.

\section{Results and Discussion}

\subsection{Flare Heat Radiation along the Pavement}

The case of interest in the present study involved flaring 275 tons/h (Case 1) natural gas from a $60 \mathrm{~m}$ tall flare stack in $10 \mathrm{~m} / \mathrm{s}$ wind blowing toward a pavement $80 \mathrm{~m}$ away, as sketched in Figure 1 . The ambient air temperature was $20^{\circ} \mathrm{C}$ and the relative humidity was $60 \%$. The resulting flare radiation at about shoulder/head level as a function of distance along the pavement is shown in Figure 3. For the modeling of skin temperatures and skin damage integral as a person is walking along the pavement under a gradually decreasing flare stack heat flux, it is convenient to fit a polynomial expression to the calculated heat flux levels. A sixth-order polynomial was therefore fitted to the calculated radiation levels.

$$
y=a+b \cdot x+c \cdot x^{2}+d \cdot x^{3}+e \cdot x^{4}+f \cdot x^{5}+g \cdot x^{6}\left(\mathrm{~kW} / \mathrm{m}^{2}\right)
$$

Table 2. Flare rate, wind speed, relative humidity for the heat radiation modeling, as well as the constants of Equation (14) and the corresponding regression coefficient (squared). The constant of Equation (15) is also given for the selected cases.

\begin{tabular}{ccccc}
\hline Constants & Case 1 & Case 2 & Case 3 & Case 4 \\
\hline Rate $($ ton $/ \mathrm{h})$ & 175 & 300 & - & - \\
Wind $(\mathrm{m} / \mathrm{s})$ & 20 & 10 & 10 & 10 \\
$\mathrm{RH}$ & $60 \%$ & $60 \%$ & - & - \\
$a$ & 2.370 & 2.850 & 3.16 & 4.0 \\
$b$ & $1.9551 \times 10^{-3}$ & $2.0025 \times 10^{-3}$ & $2.2203 \times 10^{-3}$ & $2.8105 \times 10^{-3}$ \\
$c$ & $-3.0078 \times 10^{-4}$ & $-2.8279 \times 10^{-4}$ & $-3.1355 \times 10^{-4}$ & $-3.9690 \times 10^{-4}$ \\
$d$ & $1.5213 \times 10^{-6}$ & $1.1118 \times 10^{-6}$ & $1.2327 \times 10^{-6}$ & $1.5604 \times 10^{-6}$ \\
$e$ & $6.3191 \times 10^{-9}$ & $7.3854 \times 10^{-9}$ & $8.1887 \times 10^{-9}$ & $1.0365 \times 10^{-8}$ \\
$f$ & $-6.7819 \times 10^{-11}$ & $-6.0525 \times 10^{-11}$ & $-6.7108 \times 10^{-11}$ & $-8.4947 \times 10^{-11}$ \\
$g$ & $1.4289 \times 10^{-13}$ & $1.1527 \times 10^{-13}$ & $1.2708 \times 10^{-13}$ & $1.6178 \times 10^{-13}$ \\
$R^{2}$ & 0.99987 & 0.99993 & - & - \\
$\xi(\mathrm{kW})$ & 17,901 & 26,147 & 28,991 & 36,697 \\
Sun $\left(\mathrm{kW} / \mathrm{m}^{2}\right)$ & 700 & 700 & 700 & 700 \\
\hline
\end{tabular}

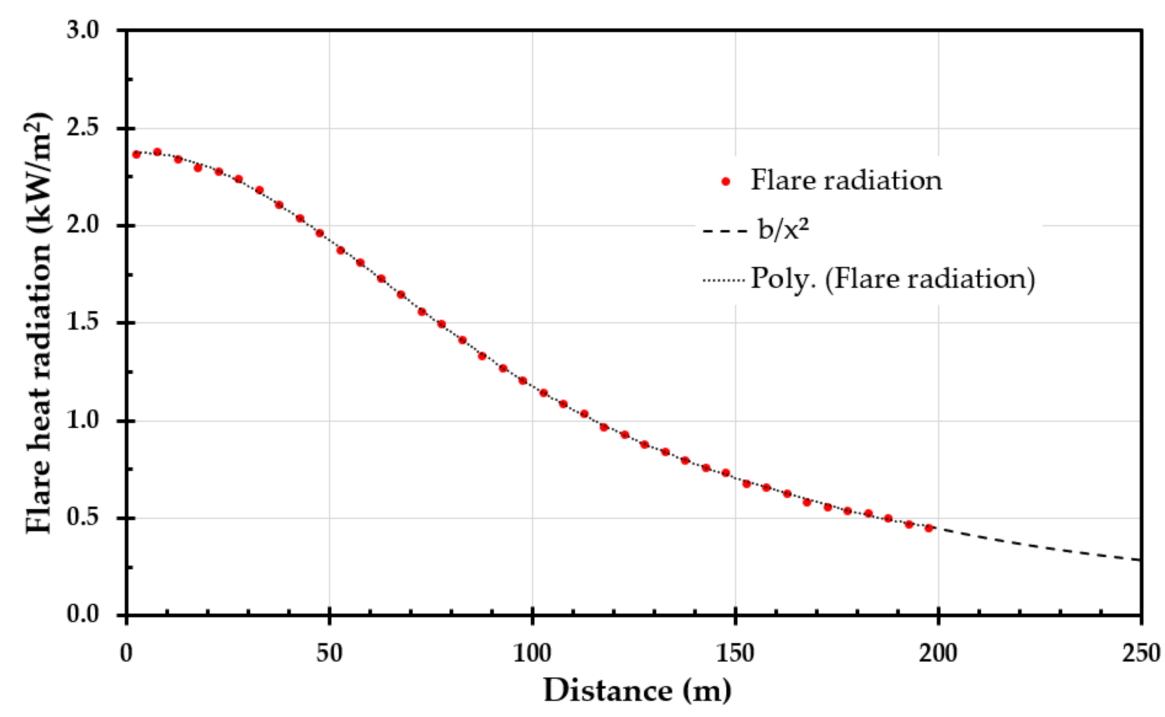

Figure 3. Net maximum flare heat radiation along the pavement for Case 1, Table 2. 
Outside the region where heat radiation data were available, i.e., outside the $200 \mathrm{~m}$ domain used in the CFD modeling, the flare radiation was assumed to originate from a point source, i.e., the heat radiation levels in that region approximately decreased with the distance, $x(\mathrm{~m})$, squared as follows:

$$
y=\xi / x^{2}\left(\mathrm{~kW} / \mathrm{m}^{2}\right)
$$

The heat radiation as a function of distance along the pavement modeled by Kameleon FireEx is shown in Figure 3. The heat radiation given by Equation (14) and Equation (15) with the respective constants given in Table 2 is also shown in the figure. Table 2 also contains details about the flare modeling for this case, denoted Case 1, i.e., flaring rate, wind conditions, and relative humidity. Similar details for other cases used for skin temperature and damage integral modeling are also given in Table 2.

Case 2 represents a higher flaring rate, i.e., 300 tons $/ \mathrm{h}$. Case 3 and Case 4 were designed by multiplying the constants of Case 2 to obtain $3.16 \mathrm{~kW} / \mathrm{m}^{2}$ and $4.0 \mathrm{~kW} / \mathrm{m}^{2}$ flare radiation heat flux at the most exposed point on the pavement at shoulder height. This allowed for checking the influence of increased flare heat flux levels on possible skin burn damages. For comparison, the flare heat radiation for all the four cases along the pavement is presented in Figure 4.

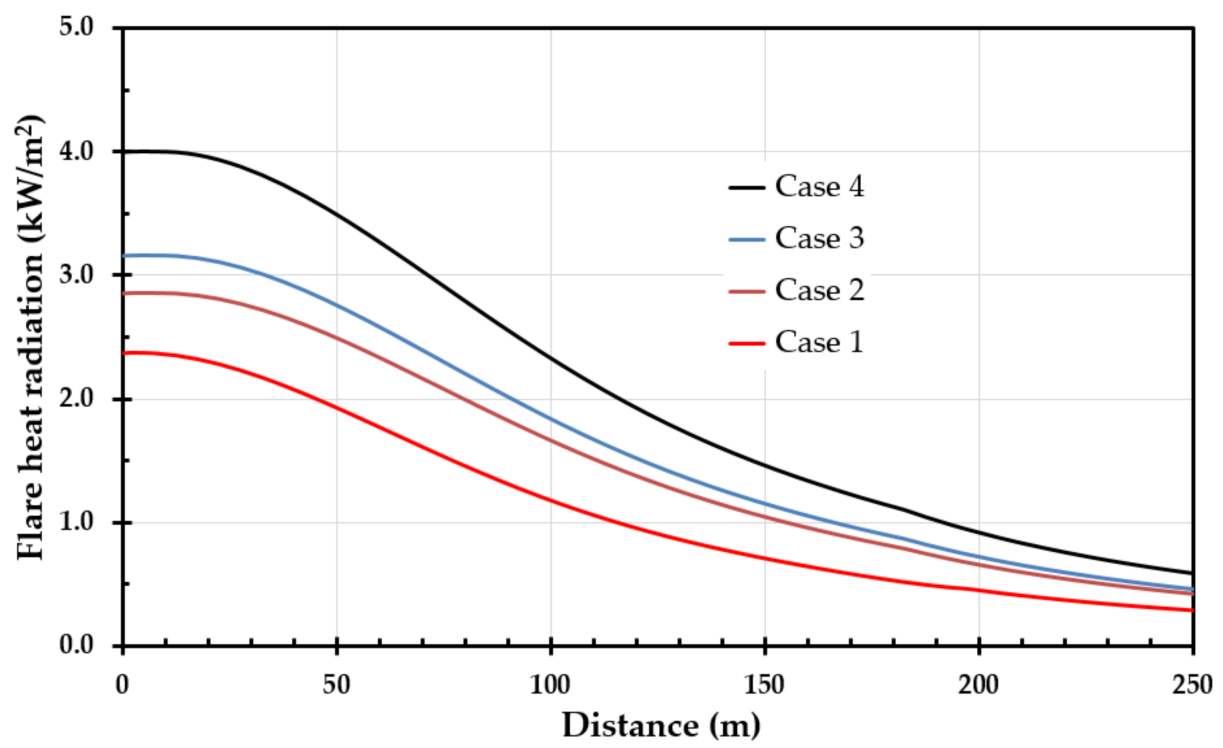

Figure 4. Net maximum flare heat radiation along the pavement for Cases 1, 2, 3, and 4, Table 2.

It should be noted that the regression coefficients obtained when fitting Equation (11) to the modeled heat radiation was generally very close to 1.0. This indicates that the approximation gives a sound estimate of the heat radiation to potentially exposed passersby at the pavement. The radiant heat exposure to a person on the pavement walking away from the ignited flare may then be calculated when the position along the pavement is known.

The worst case is that a person is at $x=0$, i.e., at the point closest to the flare, just as the flaring is initiated. It may also be anticipated that the person does not immediately start walking away but may stop and look at the flare for a short time, $t_{\mathrm{o}}(\mathrm{s})$. The person may be shocked when the flaring starts and thus check what is transpiring before realizing the importance of escaping the danger of the heat source and start moving away from the heat radiation and the high flare noise levels. Assuming that the person then walks away along the pavement at speed $u(\mathrm{~m} / \mathrm{s})$, his/her location at time $t>t_{\mathrm{o}}$ may then be calculated by $x=u \cdot\left(t-t_{\mathrm{o}}\right)$, where $t(\mathrm{~s})$ is time. Based on the distance $x$, the current heat exposure is then calculated by Equation (14). 
According to Browning et al. [35], the typical walking speed for grownups are $1.4 \mathrm{~m} / \mathrm{s}$. In stressed situations, most people would not have difficulties increasing this speed to, and even above, e.g., $2.0 \mathrm{~m} / \mathrm{s}$, though it would be tiresome in the long run. Thus, we may assume that the passerby will be exposed to the heat flux from the flare radiation as a function of walking time, as presented in Figure 5.

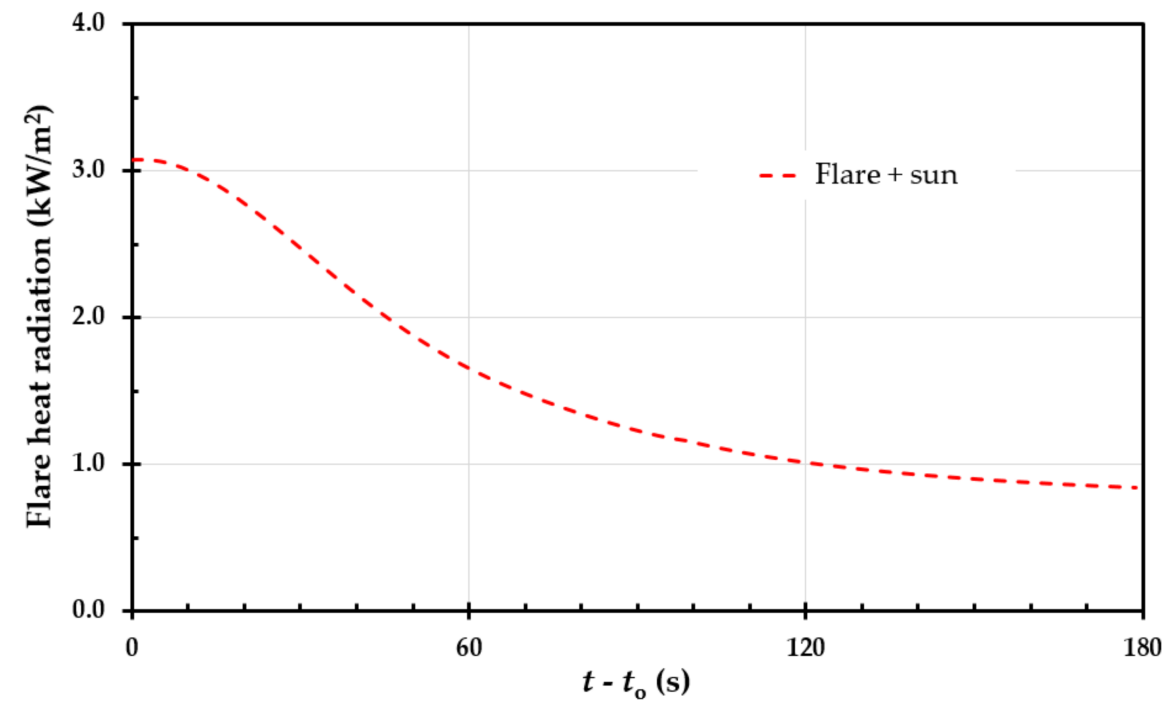

Figure 5. The total (flare $+700 \mathrm{~W} / \mathrm{m}^{2}$ solar radiation) heat flux as a function of time to a passerby evacuating from the most exposed area at a speed of $2 \mathrm{~m} / \mathrm{s}$ (based on data for Case 1, Table 2).

It should be noted that when fleeing, the angle of the flare radiation will change, i.e., the skin initially perpendicular to the flare heat radiation will receive the heat radiation gradually at a reduced angle. Thus, the heat radiation will be somewhat reduced at the originally most heat-affected area and affect skin areas not previously that exposed. Given a conservative approach, this was not taken into consideration in the skin damage modeling.

\subsection{Skin Damage Modeling}

The basal layer and $0.8 \mathrm{~mm}$ depth skin temperature and the corresponding damage integral development versus time for Case 1 are shown in Figure 6. It may be seen from the figure that the temperature level that gives pain is achieved at about $18 \mathrm{~s}$ and continues until about $92 \mathrm{~s}$. The damage integral is, however, significantly below the limit for superficial burns, i.e., significantly below $\Omega=0.53$. Thus, the passerby would not experience any superficial burns during this heat exposure.

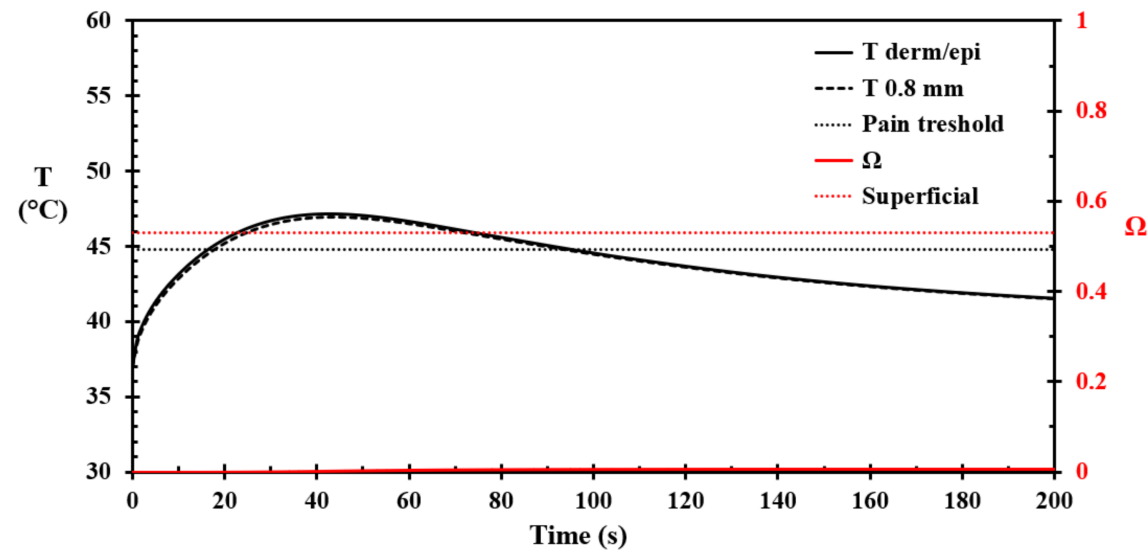

Figure 6. The basal layer and $0.8 \mathrm{~mm}$ depth skin temperature, and the corresponding damage integral development, versus time for Case 1. 
Similar data for Case 2 are shown in Figure 7. The pain limit is reached earlier, i.e., at about $13 \mathrm{~s}$, and the period of pain lasts to about $135 \mathrm{~s}$. Additionally, in this case, there is a very clear margin to skin burns, as indicated by a damage integral still significantly lower than $\Omega=0.53$.

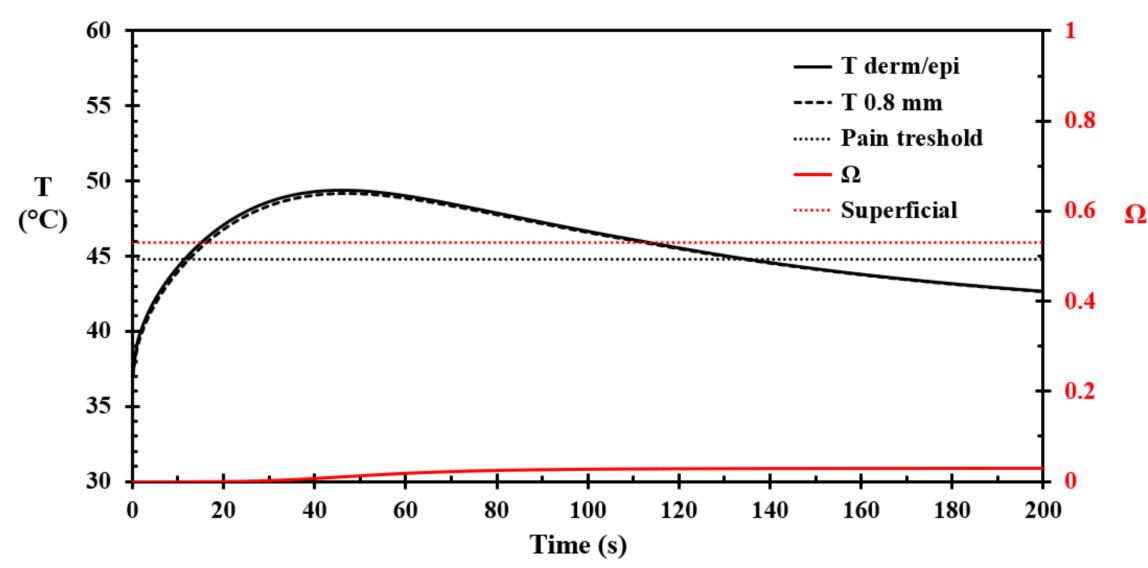

Figure 7. The basal layer and $0.8 \mathrm{~mm}$ depth skin temperature, and the corresponding damage integral development, versus time for Case 2.

The AISI regulations operate with $1.56 \mathrm{~kW} / \mathrm{m}^{2}$ as the heat radiation limit for infinite exposure. It is known that some companies have used the double of this value, i.e., $3.16 \mathrm{~kW} / \mathrm{m}^{2}$, as a limit for short-time passerby heat exposure. Case 3 in Table 2 is based on Case 2, by multiplying the flare heat exposure by 1.109 to obtain $3.16 \mathrm{~kW} / \mathrm{m}^{2}$ as the flare heat flux to the most exposed point at the pavement. Though this does not strictly correlate to a given flare rate, it may give valuable information about the increased heat exposure. It should be noted that not only the maximum heat exposure is increased but also the time period the passerby is exposed to flare heat exposure above, e.g., $1.56 \mathrm{~kW} / \mathrm{m}^{2}$. The basal layer and $0.8 \mathrm{~mm}$ depth skin temperature and the corresponding damage integral development versus time for Case 3 are shown in Figure 8. It may be seen from the figure that the temperature level that induces pain is achieved at about $10 \mathrm{~s}$ and continues until about $150 \mathrm{~s}$. The damage integral is, however, still significantly below the limit for superficial burns, i.e., $\Omega=0.53$. Thus, the passerby would not experience superficial burns during this heat exposure.

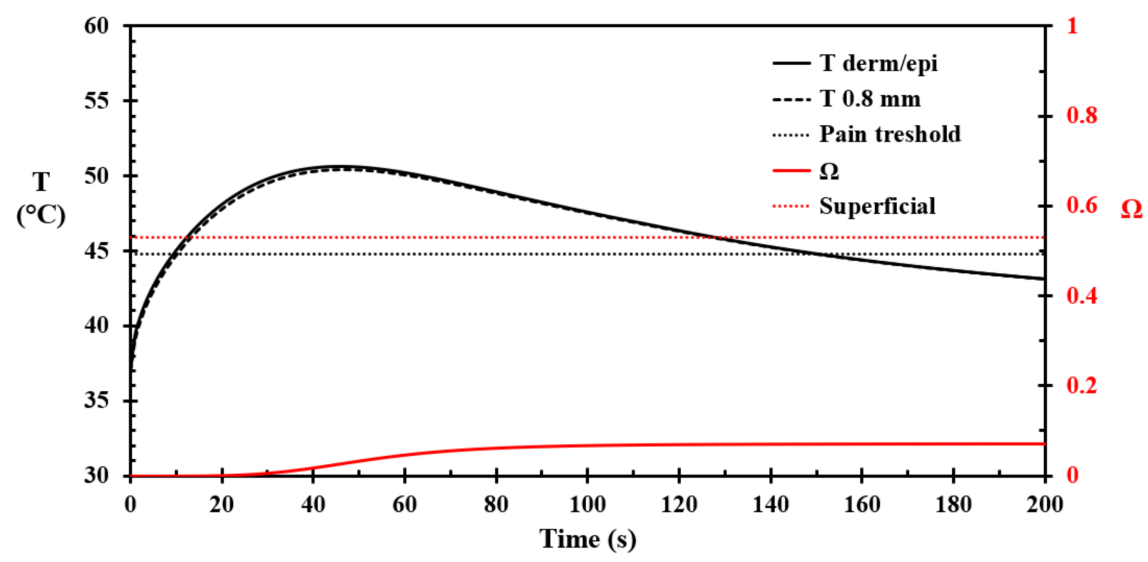

Figure 8. The basal layer and $0.8 \mathrm{~mm}$ depth skin temperature, and the corresponding damage integral development, versus time for Case 3, i.e., $3.16 \mathrm{~kW} / \mathrm{m}^{2}$ as the flare heat flux to the most exposed point at the pavement.

Case 4 in Table 2 is also based on Case 2, where the heat exposure as a function of distance was multiplied by 1.404 to obtain $4.0 \mathrm{~kW} / \mathrm{m}^{2}$ as the flare heat flux to the most 
exposed point at the pavement. The basal layer and $0.8 \mathrm{~mm}$ depth skin temperature, and the corresponding damage integral development versus time for Case 4 are shown in Figure 9. It may be seen from the figure that the temperature level that induces pain is achieved at about $7 \mathrm{~s}$ and continues until about $190 \mathrm{~s}$. Additionally, in this case, the damage integral is $\Omega=0.71$ (0.709), which is well above the limit for superficial burns, i.e., $\Omega=0.53$. Thus, the passerby would experience superficial burns after this heat exposure unless being able to shield any exposed skin.

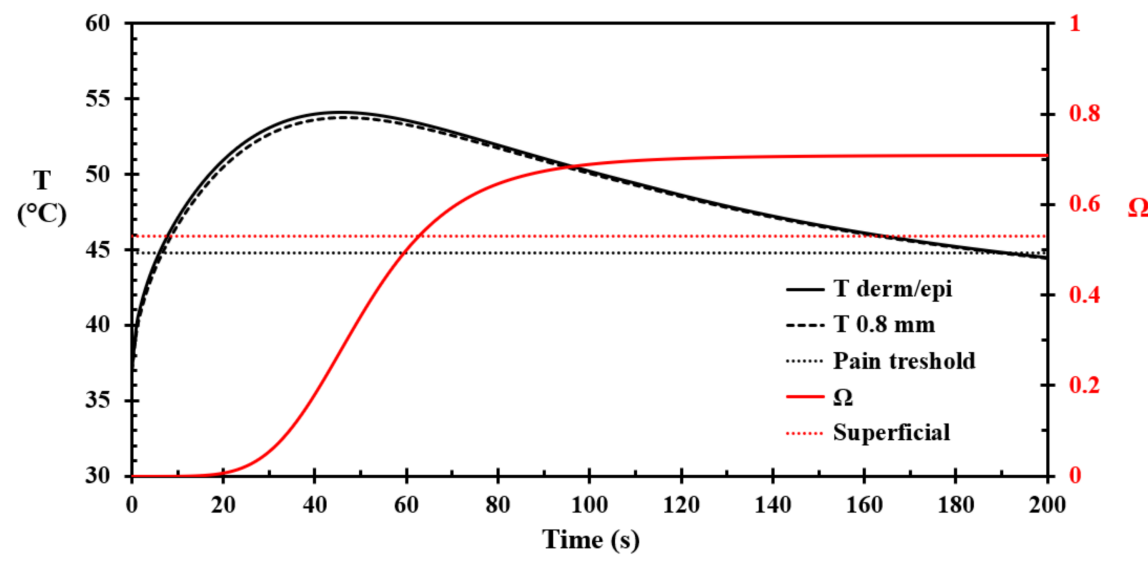

Figure 9. The basal layer and $0.8 \mathrm{~mm}$ depth skin temperature, and the corresponding damage integral development, versus time for Case 4, i.e., $4.0 \mathrm{~kW} / \mathrm{m}^{2}$, as the flare heat flux to the most exposed point at the pavement.

The $10 \mathrm{~s}$ delay in starting to move from the most exposed part of the pavement may not be very realistic in a flaring scenario. It was, therefore, decided to analyze the influence of the delay on the skin damage integral. Fore Case 4, reducing the delay, $t_{0}$, from $10 \mathrm{~s}$ to $5 \mathrm{~s}$ decreased the damage integral from 0.71 to 0.39 , while zero delays further decreased the damage integral to 0.21 . These results clearly show that it is very important to quickly start moving away from zones of high radiant heat fluxes.

The damage integral increased quite substantially from Case 3 to Case 4 . This also indicates that the difference between a seemingly safe heat radiation level to radiation levels that make skin damage is indeed not very large.

The convective heat transfer coefficient was conservatively set to $20 \mathrm{~W} / \mathrm{m}^{2} \mathrm{~K}$. Using the data for Case 4 and a heat transfer coefficient of $25 \mathrm{~W} / \mathrm{m}^{2} \mathrm{~K}$ reduced the modeled skin damage integral from 0.71 to 0.40 , i.e., to below the limit of superficial skin burns.

The solar radiation was, as default, set to $700 \mathrm{~W} / \mathrm{m}^{2}$. Assuming partly cloudy conditions and $350 \mathrm{~W} / \mathrm{m}^{2}$ heat radiation, reduced the damage integral for Case 4 from 0.71 to 0.21 , while zero solar radiation further reduced the damage integral to 0.06 .

The reason for the "volatility" in the damage integral is due to two factors-the exponential influence of the skin temperature on the damage integral and the linear dependence on time. Given this volatility, it is not possible to precisely calculate skin damage without very detailed knowledge about the situation at hand. The calculations may, however, show at which radiant heat exposure levels different skin damage may be expected, and below which levels skin burns may not be expected.

It should be noted that in the close vicinity to a regular flare or an unintentionally ignited cold flare, the radiative heat flux levels are much higher than the values analyzed in the present study. However, inside the industrial site perimeter, the zone closest to such equipment is generally considered a sterile zone with very infrequent work, and the workers are generally equipped with clothing that protects against much higher heat fluxes [36,37]. Thus, exposure to very high heat fluxes that may generate deeper burns, e.g., deep partial-thickness burns [38], is outside the current study, which focused on low heat radiation levels. 
In modeling and testing scenarios for the development of skin burns, very many parameters determine the outcome of the heat exposure. In the study performed by Yang et al. [14], the heat flow to the skin increased to about $2 \mathrm{~kW} / \mathrm{m}^{2}$ during $180 \mathrm{~s}$ heat exposure. They recorded an additional 10-15 s increase in skin surface temperature after the heat exposure, i.e., during the cooling, due to accumulated heat in the firefighting garments. High net heat flux to the skin late in the heat exposure period has previously been shown to cause more skin burns than a similar high heat flux peak early in the heat exposure [16]. The long-time exposure during physical work by Zhang et al. [15] for persons in underwear exposed to $2 \mathrm{~kW} / \mathrm{m}^{2}$ heat flux to naked skin in stagnant air (less than $0.1 \mathrm{~m} / \mathrm{s}$ ) included sweating. They did not report any skin burns. Though it is very difficult to compare these results, it may be argued that the present study complies with these studies [14,15]. It may be concluded that in the present study, an early comparably high heat flux being reduced while fleeing allows the heat to be dissipated in the skin while fleeing, thereby reducing the skin injury. The convective cooling also reduces the net heat flux to the skin in the present study, and the higher the skin surface temperature is, the more heat is lost convectively.

The novel concept of modeling skin damage to fleeing persons also opens up for modeling traveling through, e.g., constructions shielding direct heat radiation from the flare and the sun. For the future, this could be interesting regarding safety evaluations prior to necessary maintenance work in the sterile zone close to flares and cold vents where the heat radiation levels in an emergency flaring could become quite high. This will likely be of interest in future studies.

Given the flaring scenarios and distances analyzed in the present study, it appears that heat flux levels up to $3.16 \mathrm{~kW} / \mathrm{m}^{2}$ may be acceptable at a pavement where passersby may occasionally be present. It should, however, be noted that this should be evaluated for each site of interest, as very many parameters may influence the results, e.g., the type of gas to be flared, the height of the flare stack, the extent of the radiation field, as well as wind and sun conditions. It was, however, demonstrated that the novel method outlined and tested in the present study is effective and that it may be used in future studies analyzing each influencing parameter in greater detail.

\section{Conclusions}

Heat radiation exposure of a possible bold or bare shoulder passersby exposed when flaring from a natural gas facility was investigated, including solving the Pennes bioheat equation for the person walking on an adjacent pavement. For the studied case, a maximum level of twice the API 521 recommended $1.58 \mathrm{~kW} / \mathrm{m}^{2}$, i.e., $3.16 \mathrm{~kW} / \mathrm{m}^{2}$, added $0.7 \mathrm{~kW} / \mathrm{m}^{2}$ solar radiation, did not give superficial ("first-degree") skin burns when walking at $2 \mathrm{~m} / \mathrm{s}$ away along a pavement perpendicular to the flare plume. However, for larger flares, i.e., with a larger heat radiation footprint, the burns could develop due to expected higher maximum heat radiation levels as well as increased exposure time while escaping. Increased exposure time resulted in both higher basal layer temperatures and longer exposure time, thus increasing the damage integral significantly. Under such conditions, a seemingly minor increase in heat radiation may increase the skin burns from superficial ("first-degree") to superficial partial-thickness ("second-order") burns. It is important that each case is analyzed individually.

Funding: This research received no external funding.

Institutional Review Board Statement: Not applicable.

Informed Consent Statement: Not applicable.

Data Availability Statement: Data available on request. 
Acknowledgments: The Cameleon FireEx example data supplied by Andrea Risan, Vysus consulting, are highly appreciated. Fruitful discussions with Diana Osk Olafsdottir Risløv, Gassco, are also highly appreciated. The improvements of the manuscript suggested by three anonymous reviewers are also much appreciated.

Conflicts of Interest: The author declares no conflict of interest. The funders had no role in the design of the study; in the collection, analyses, or interpretation of data; in the writing of the manuscript, or in the decision to publish the results.

\section{References}

1. Henriques, F.C.; Moritz, A.R. Studies of thermal injury: I. The conduction of heat to and through skin and the temperatures attained therein. A theoretical and an experimental investigation. Am. J. Pathol. 1947, 23, 530-549.

2. Moritz, A.; Henriques, F.C. Studies of thermal injury: II. The relative importance of time and surface temperature in the causation of cutaneous burns. Am. J. Pathol. 1947, 23, 695-720.

3. Moritz, A.R. Studies of thermal injury: III. The pathology and pathogenesis of cutaneous burns: An experimental study. Am. J. Pathol. 1947, 23, 915-941.

4. Fu, M.; Weng, W.G.; Yuan, H.Y. Numerical simulation of the effects of blood perfusion, water diffusion, and vaporization on the skin temperature and burn injuries. Numer. Heat Transf. Part A Appl. 2014, 65, 1187-1203. [CrossRef]

5. Tobalem, M.; Harder, Y.; Tschanz, E.; Speidel, V.; Pittet-Cuénod, B.; Wettstein, R. First-aid with warm water delays burn progression and increases skin survival. J. Plast. Reconstr. Aesthet. Surg. 2013, 66, 260-266. [CrossRef] [PubMed]

6. Johnson, N.N.; Abraham, J.P.; Helgeson, Z.I.; Minkowycz, W.J.; Sparrow, E.M. An archive of skin-layer thicknesses and properties and calculations of scald burns with comparisons to experimental observations. J. Therm. Sci. Eng. Appl. 2011, 3. [CrossRef]

7. Monds, J.R.; McDonald, A.G. Determination of skin temperature distribution and heat flux during simulated fires using Green's functions over finite-length scales. Appl. Therm. Eng. 2013, 50, 593-603. [CrossRef]

8. Buettner, K. Effects of extreme heat and cold on human skin, II. Surface temperature, pain and heat conductivity in experiments with radiant heat. J. Appl. Physiol. 1951, 3, 703-713. [CrossRef] [PubMed]

9. Lawrence, J.C.; Bull, J.P. Thermal conditions which cause skin burns. Eng. Med. 1976, 5, 61-63. [CrossRef]

10. Log, T. Skin temperatures of a pre-cooled wet person exposed to engulfing flames. Fire Saf. J. 2017, 89, 1-6. [CrossRef]

11. Abraham, J.P.; Plourde, B.; Vallez, L.; Stark, J.; Diller, K.R. Estimating the time and temperature relationship for causation of deep-partial thickness skin burns. Burns 2015, 41, 1741-1747. [CrossRef]

12. Abraham, J.P.; Nelson-Cheeseman, B.B.; Sparrow, E.; Wentz, J.E.; Gorman, J.M.; Wolf, S.E. Comprehensive method to predict and quantify scald burns from beverage spills. Int. J. Hyperth. 2016, 32, 900-910. [CrossRef]

13. Abraham, J.P.; Hennessey, M.P.; Minkowycz, W.J. A simple algebraic model to predict burn depth and injury. Int. Commun. Heat Mass Transf. 2011, 38, 1169-1171. [CrossRef]

14. Yang, J.; Su, Y.; Song, G.; Li, R.; Xiang, C. A new approach to predict heat stress and skin burn of firefighter under low-level thermal radiation. Int. J. Therm. Sci. 2019, 145, 106021. [CrossRef]

15. Zhang, S.; Zhu, N.; Lv, S. Human response and productivity in hot environments with directed thermal radiation. Build. Environ. 2021, 187, 107408. [CrossRef]

16. Log, T. Modeling Burns for Pre-Cooled Skin Flame Exposure. Int. J. Environ. Res. Public Health 2017, 14, 1024. [CrossRef]

17. Ng, E.Y.K.; Chua, L.T. Prediction of skin burn injury, Part 2: Parametric and sensitivity analysis. Proc. Inst. Mech. Eng. Part H J. Eng. Med. 2002, 216, 171-183. [CrossRef]

18. Lipkin, M.; Hardy, J.D. Measurement of some thermal properties of human tissues. J. Appl. Physiol. 1954, 7, 212-217. [CrossRef]

19. Rai, K.N.; Rai, S.K. Heat transfer inside the tissues with a supplying vessel for the case when metabolic heat generation and blood perfusion are temperature dependent. Heat Mass Transf. 1999, 35, 345-350. [CrossRef]

20. Soerensen, D.D.; Clausen, S.; Mercer, J.B.; Pedersen, L.J. Determining the emissivity of pig skin for accurate infrared thermography. Comput. Electron. Agric. 2014, 109, 52-58. [CrossRef]

21. Shitzer, A. Wind-chill-equivalent temperatures: Regarding the impact due to the variability of the environmental convective heat transfer coefficient. Int. J. Biometeorol. 2006, 50, 224-232. [CrossRef]

22. Osczevski, R.J. The basis of wind chill. Arctic 1995, 48, 372-382. [CrossRef]

23. Log, T.; Gustafsson, S.E. Transient Plane Source (TPS) technique for measuring thermal transport properties of building materials. Fire Mater. 1995, 19, 43-49. [CrossRef]

24. Millington, P.F.; Wilkinson, R. Skin; Cambridge University Press: New York, NY, USA, 1983.

25. Viglianti, B.L.; Dewhirst, M.W.; Abraham, J.P.; Gorman, J.-M.; Sparrow, E.M. Rationalization of thermal injury quantification methods: Application to skin burns. Burns 2014, 40, 896-902. [CrossRef] [PubMed]

26. Henriques, F.C.; Moritz, A. Studies of thermal injury, V: The predictability and the significance of thermal induced rate processes leading to irreversible epidermal injury. Arch. Pathol. 1947, 44, 489-502.

27. Ye, H.; De, S. Thermal injury of skin and subcutaneous tissues: A review of experimental approaches and numerical models. Burns 2017, 43, 909-932. [CrossRef]

28. Vembe, B.E.; Lilleheie, N.I.; Holen, J.; Magnussen, B.F.; Velde, B.; Linke, G.; Genillon, P. Kameleon FireExd-A simulator for gas dispersion and fires. In Proceedings of the International Gas Research Conference, San Diego, CA, USA, 8-11 November 1998. 
29. ComputIT. Kameleon FireEx 2000 Theory Manual; ComputIT: Trondheim, Norway, 2001.

30. Magnussen, B.F.; Evanger, T.; Vembe, B.E.; Lilleheie, N.I.; Grimsmo, B.; Velde, B.; Holen, J.; Linke, G.; Genillon, P.; Tonda, H.; et al. Kameleon FireEx in Safety Applications; SPE International: Stavanger, Norway, 2000.

31. Evanger, T.; Holmås, T. Kameleon FireExdan Advanced Computational System for Calculation of Fire Structure Interaction; Fabig Technical Newsletter, Issue 41; The Steel Construction Institute: Chicago, IL, USA, 2005.

32. Jang, C.B.; Choi, S.W. Simulation and Damage Analysis of an Accidental Jet Fire in a High-Pressure Compressed Pump Shelter. Saf. Health Work 2017, 8, 42-48. [CrossRef]

33. Rothmana, L.S.; Gordona, I.E.; Babikovb, Y.; Barbec, A.; Chris, B.D.; Bernathe, P.F.; Birkf, M.; Bizzocchig, L.; Boudonh, V.; Browni, L.R.; et al. The HITRAN2012 Molecular Spectroscopic Database. J. Quant. Spectrosc. Radiat. Transf. 2013, 130, 4-50. [CrossRef]

34. Mikhailenko, S.N.; Babikov, Y.L.; Golovko, V.F. Information-calculating system Spectroscopy of Atmospheric Gases. The structure and main functions. Inst. Atmos. Opt. 2005, 18, 685-695.

35. Browning, R.C.; Baker, E.A.; Herron, J.A.; Kram, R. Effects of obesity and sex on the energetic cost and preferred speed of walking. J. Appl. Physiol. 2006, 100, 390-398. [CrossRef] [PubMed]

36. Mandal, S.; Mazumder, N.U.S.; Agnew, R.J.; Grover, I.B.; Song, G.; Li, R. Using Artificial Neural Network Modeling to Analyze the Thermal Protective and Thermo-Physiological Comfort Performance of Textile Fabrics Used in Oilfield Workers' Clothing. Int. J. Environ. Res. Public Health 2021, 18, 6991. [CrossRef] [PubMed]

37. Mandal, S.; Mazumder, N.U.S.; Agnew, R.J.; Song, G.; Li, R. Characterization and Modeling of Thermal Protective and ThermoPhysiological Comfort Performance of Polymeric Textile Materials-A Review. Materials 2021, 14, 2397. [CrossRef] [PubMed]

38. Gibson, A.L.F.; Carney, B.C.; Cuttle, L.; Andrews, C.J.; Kowalczewski, C.J.; Liu, A.; Powell, H.M.; Stone, R.; Supp, D.M.; Singer, A.J.; et al. Coming to Consensus: What Defines Deep Partial Thickness Burn Injuries in Porcine Models? J. Burn. Care Res. 2020, 42, 98-109. [CrossRef] [PubMed] 